\title{
Hybrid Composites of Phosphate Glass Fibre/Nano-Hydroxyapatite/Polylactide: Effects of Nano-Hydroxyapatite on Mechanical Properties and Degradation Behaviour
}

\author{
Lizhe He1, Chenkai Zhu',2, Jiahao Wu ${ }^{3}$, Xiaoling Liu ${ }^{3 *}$ \\ ${ }^{1}$ Ningbo Nottingham International Academy for the Marine Economy and Technology, University of Nottingham Ningbo China, \\ Ningbo, China \\ ${ }^{2}$ Ningbo Nottingham New Materials Institute, University of Nottingham Ningbo China, Ningbo, China \\ ${ }^{3}$ Faculty of Science and Engineering, University of Nottingham Ningbo China, Ningbo, China \\ Email: *Xiaoling.Liu@nottingham.edu.cn
}

How to cite this paper: He, L.Z., Zhu, C.K., Wu, J.H. and Liu, X.L. (2018) Hybrid Composites of Phosphate Glass Fibre/NanoHydroxyapatite/Polylactide: Effects of NanoHydroxyapatite on Mechanical Properties and Degradation Behaviour. Journal of Materials Science and Chemical Engineering, 6, 13-31.

https://doi.org/10.4236/msce.2018.611002

Received: October 29, 2018

Accepted: November 27, 2018

Published: November 30, 2018

Copyright $\odot 2018$ by authors and Scientific Research Publishing Inc. This work is licensed under the Creative Commons Attribution International License (CC BY 4.0).

http://creativecommons.org/licenses/by/4.0/ (c) (i) Open Access

\begin{abstract}
Hydroxyapatite/polylactide (HA/PLA) composites have been intensively investigated for their potential as biodegradable fixation devices to heal bone fractures. However, most of these composites failed to achieve a bone-mimicking level of mechanical properties, which is an essential demand of the targeted application. In this study, the nano-hydroxyapatite/polylactide composites were used as the matrix and continuous phosphate glass fibres (PGF) served as the major reinforcement to obtain the nano-HA/PGF/PLA hybrid composites. While the PGF volume fraction remained constant (25\%), the nano-HA content (in weight) varied from $0 \%$ to $20 \%$. As nano-HA loading increased, the flexural modulus of the composites increased from $8.70 \pm$ $0.35 \mathrm{GPa}$ to $14.97 \pm 1.30 \mathrm{GPa}$, and the flexural strengths were enhanced from $236.31 \pm 10.83 \mathrm{MPa}$ to $310.55 \pm 22.88 \mathrm{MPa}$. However, it is found that the degradation rates are higher with more nano-HA loaded. Enhanced water absorption ability, as well as increased voids in the composites is possible reasons for the accelerated degradation of composites with higher nano-HA loading. The hybrid composites possess mechanical properties that are superior to most of the HA/PLA composites in previous research while maintaining the biodegradability. With a proper loading of nano-HA in composites of 10 weight percent, the composites are also found with improved mechanical properties without catastrophic degradation. The composites developed in this study have great potential as biodegradable bone fixation device with enhanced load-bearing ability as confirmed and superior bioactivity as anticipated.
\end{abstract}




\section{Keywords}

Phosphate Glass Fibres, Polylactide, Hydroxyapatite, Hybrid Composites, Mechanical Properties

\section{Introduction}

Stabilization of fractured sites is essential in the healing process of bone fractures. The most common practice nowadays is implantation of internal fixation devices, such as fixation plates and screws, to limit the strain of fractured bone segments for endochondral osteogenesis [1]. Regarding the materials of fixation devices, metals including stainless steel, $\mathrm{Co}-\mathrm{Cr}$ - $\mathrm{Al}$ alloys and titanium alloys are most commonly used due to excellent mechanical strengths, good biocompatibility, cost-effective manufacturing and ease of handling [1] [2]. However, many problems arise with the use of metallic implants. The corrosion of metals results in loosening of implants and release of metal ions $(\mathrm{Cr}, \mathrm{Co}, \mathrm{Ni}$, etc.) which lead to severe long-term damage to organ [2] [3]. The mismatching of mechanical stiffness between metals and human cortical bone might lead to stress shielding of the new bones, resulting in osteoporosis of regrown bones and risks of secondary bone fractures [4]. Finally, secondary surgeries to remove the implants after recovery might bring further complications and pains to the patients [5]. It is therefore considered that to eliminate the problems mentioned above, the novel materials shall possess bone-mimicking mechanical properties so that the implant is just stiff enough for the load-bearing activities in daily life without triggering the stress-shielding. Meanwhile, the implant should be fully resorbed/degraded in the human body after the healing process is done.

Polylactide (PLA) is considered a candidate material for biodegradable orthopaedic implants due to excellent biocompatibility and the ability to complete biodegradation in the term ranging from 10 months to 4 years [5] [6] [7]. Nevertheless, the elastic modulus of PLA alone is much inferior to those of human cortical bones, calling for reinforcements with high stiffness to be incorporated in PLA matrix, so that the composites possess higher modulus and the consequent enhanced load-bearing ability for fracture fixation [8]. One of the most studied reinforcements is hydroxyapatite (HA) [9] [10] [11] [12]. It is the main component of the inorganic phase in human bones and has an excellent affinity towards native bones. Therefore, it has been widely applied as a bioactive agent (e.g. coating) to improve the bonding strength between HA coated/containing implants and native bone structures [7]. Additionally, the high stiffness (modulus ranging from 80 to $110 \mathrm{GPa}$ [13]) makes it a common reinforcement in polymer composites for biomedical application. An impressive research by Shikinami et al. reported that the forged HA/PLA composites possess mechanical properties mimicking human cortical bones, and more importantly, with excellent bone-union bioactivity and bioresorbability evidenced by a 5-year in-vivo implantation study [14] [15] [16]. Except for this series of research, however, few 
studies succeeded in fabricating the HA/PLA composites with bone-mimicking mechanical properties. Therefore, the HA/PLA composites are rarely applied as bone fixation device where excellent load-bearing ability is demanded.

To further improve the mechanical properties of HA/PLA composites, an idea is to incorporate fibres as major mechanical reinforcement, while the HA serves as secondary reinforcement and bioactive agents. Shen et al. reported that the incorporation of nano-hydroxyapatite (nano-HA) improved the bending strengths and moduli of unidirectional carbon fibre/nano-HA/PLA composites, which peaked at $430 \mathrm{MPa}$ and $22 \mathrm{GPa}$ respectively and were close to the upper limit of human cortical bones [17]. Su et al. prepared chopped glass fibres/nano-HA/polyamide 66 composite screws/plates via injection moulding. The composites possess bone-mimicking mechanical properties, good biocompatibility and the HA contributed to enhanced bone union strength comparing to titanium counterparts [18]. However, these composites were partially degradable, and the leftover components might lead to further complications.

In order to improve the mechanical properties of HA/PLA composites while maintaining the biodegradability, phosphate glass fibre (PGF) is chosen as the fibre reinforcement in this study. The phosphate glasses fibre possess high tensile modulus (40 - $80 \mathrm{GPa}$ ) as received [19]. When immersed in aqueous environments, the PGF dissolves slowly to release calcium, phosphate and magnesium that are beneficial for bone regrowth. The PGF has been intensively investigated as biodegradable reinforcements in the biomedical composite. Parsons et al. reported that by manipulating the contents and structure/alignments of phosphate glass fibres, the initial mechanical properties of PGF/PLA composites were optimized, with the highest initial flexural strengths and modulus reaching $350 \mathrm{MPa}$ and $30 \mathrm{GPa}$, respectively [19] [20]. The mechanical properties, as well as their retention against degradation, were further improved by surface treatment on PGF with coupling agents [20] [21] [22] [23] or surface roughening [24] [25]. Plates, rods and screws of these PGF reinforced composites were fabricated by compression moulding and forging processes [26] [27], demonstrating the excellent processing ability of PGF in biodegradable composites for biomedical application. While the PGF/PLA composites have been well known for their strength, there is currently no study that investigate the effects of replacing the one-phase PLA matrix with the HA/PLA composites. With the use of composite matrix, the mechanical properties of composites is expected to be further improved, and more importantly, the HA might contribute to improved bone-bonding activity of the implants. Prior to biological investigation begins, it is necessary to investigate the mechanical properties and the degradation behaviour of these ternary composites.

In this study, hyrbid biodegradable composites with nano-HA/PLA as matrices, unidirectional PGF as well as nano-hydroxyapatite as reinforcements were prepared by solvent casting-hot pressing process. The mechanical properties, as well as the degradation behaviour of the hybrid composites were investigated to evaluate the potential of these composites as potential biodegradable fixation de- 
vices.

\section{Materials and Methods}

\subsection{Materials}

Polylactide (3251D, Natureworks ${ }^{\oplus}$, USA) was used as thermoplastic matrix of the composites. Nano-hydroxyapatite (HAP01, Hualan Chemistry ${ }^{\oplus}$, China) was purchased from Hualan Chemistry, and phosphate glass fibres with chemical composition as (P48-B12-Mg20-Ca14-Fe5-Na1) was kindly provided by Sinoma , China [28]. Dichloromethane (DCM, 99.8\% for HPLC, Sigma-Aldrich ${ }^{\circ}$, USA) was selected as organic solvents. Phosphate buffered saline (PBS) was prepared from P4417-100TAB (Sigma-Aldrich ${ }^{\oplus}$, U.S.A.) by dissolving 1 tablet in $200 \mathrm{ml}$ of deionized water.

\subsection{Preparation of Nano-HA/PLA Composites}

The nano-HA/PLA composites were prepared via dissolution-solvent evaporation methods. For each specimen group, different amount of nano-hydroxyapatite (HAP01, Hualan Chemistry ${ }^{\oplus}$, China) was weighted and cast into $300 \mathrm{ml}$ of dichloromethane and homogenized using mechanical stirrer. Then, $40 \mathrm{~g}$ of PLA pellets were cast into the nano-HA/DCM suspension and stirred until all PLA was dissolved. The resultant nano-HA/PLA/DCM slurry was ultrasonicated for 10 minutes (JP-060S Sonicator, Skymen ${ }^{\circledR}$, China). Finally, the slurry was cast into steel dishes, left in a fume hood overnight for solvent evaporation before sent into the oven for 48 hours of vacuum drying at $45^{\circ} \mathrm{C}$. The temperature was higher than the initial boiling point of DCM for effective removal of this organic solvent [29]. The final weight fraction of nano-HA in the slurry (and consequent matrix) were controlled to be 0 (control group), 5, 10, 15, and $20 \mathrm{wt} \%$. This weight fraction number is consistent with the nano-HA loading stated in the rest of this work.

The dried nano-HA/PLA composite was placed into hot-presser (ZG-50T, Zhenggong ${ }^{\oplus}$, China) for preheating at $210^{\circ} \mathrm{C}$ for $20 \mathrm{~min}$ and pressed at $20 \mathrm{Bar}$ for $30 \mathrm{~s}$ to produce HA/PLA films with thickness around $0.2 \mathrm{~mm}$. The films were finally trimmed into $140 \mathrm{~mm} \times 128 \mathrm{~mm}$ rectangles and stored at $37^{\circ} \mathrm{C}$ for 24 hours before use.

\subsection{Preparation of Unidirectional PGF Mats}

A continuous bundle of PGFs was manually wound onto a PMMA cylinder to make the unidirectional fibre mat. These PGFs were then sprayed with $2 \mathrm{wt} \%$ PLA/DCM solution and left in a fume hood overnight for solvent evaporation, then trimmed into $140 \mathrm{~mm} \times 128 \mathrm{~mm}$ unidirectional PGF mats. The mats $(\sim 7$ $\mathrm{g} /$ piece) were stored in $37^{\circ} \mathrm{C}$ oven for 48 hours before use.

\subsection{Preparation of Hybrid Composites}

A stainless-steel mould with a $140 \mathrm{~mm} \times 128 \mathrm{~mm} \times 2 \mathrm{~mm}$ cavity was sand- 
wiched by 2 pieces of PTFE cloths and 2 stainless steel plate. 3 pieces of PGF mats and 8 pieces of nano-HA/PLA films were symmetrically sandwiched (A/B/A/B/A/B/A, where A stands for 2 nano-HA/PLA films and B stands for 1 piece of PGF mat) and inserted into the mould cavity. Such assemblies were sent into the hot-presser, heated under $210^{\circ} \mathrm{C}$ for 15 minutes, and followed by 10 -minute pressing under the static pressure of 30 Bar, then cold-pressed for 10 minutes to obtain hybrid composite plates. The pressure, temperature and processing time were determined so that the PGF within composites remained straight without curving, and voids inside the composites were minimized. With this method applied, the fibre volume fraction within the composite plates was controlled to be $\sim 25 \%$.

\subsection{Mechanical Testing}

Composites plates were cut into $40 \mathrm{~mm} \times 15 \mathrm{~mm} \times 2 \mathrm{~mm}$ specimens using a bandsaw, and polished with sanding paper to clean the edges. Then, the specimens were subjected to 3-point bending tests in accordance with BS EN ISO 14125:1998. An $\mathrm{MTS}^{\circledast}$ E45.105 universal testing machine with $50 \mathrm{kN}$ load cell was used for these tests, with the rate of the cross-head set at $1 \mathrm{~mm} / \mathrm{min}$. For each batch of test specimens, the mechanical testing was carried out in triplicate.

\subsection{Degradation Studies}

A 28-day degradation study was done to track the variation of media uptake, mass loss and flexural properties of composites. The specimens were immersed in glass vials filled with $30 \mathrm{ml}$ phosphate buffered saline and stored in $37^{\circ} \mathrm{C}$ oven (DHG-9075A, Yiheng ${ }^{\circledR}$, China). PBS was refreshed every 2 days. At the time point $1,3,7,11,14,21$ and 28 day of degradation period, specimens were taken out, blot-dried with tissue and weighted for their wet mass. Then, mechanical testing according to 2.4 was done. The tested specimens were stored in $37^{\circ} \mathrm{C}$ oven for 5 days and weighted again for dried mass. Water absorption (WA) and mass loss (ML) were calculated as below:

$$
\begin{gathered}
W A=\frac{M_{w}-M_{d}}{M_{d}} \times 100 \% \\
W L=\frac{M_{i}-M_{d}}{M_{d}} \times 100 \%
\end{gathered}
$$

where $M_{w}$ is the mass of specimens blot dried after being taken out from PBS (thus contain moisture), $M_{d}$ is the mass of specimens after 5 days of drying, and $M_{\mathrm{i}}$ is the initial mass of specimens.

\subsection{SEM Imaging}

The specimens were sputtered with $5 \mathrm{~nm}$ gold using the high vacuum film deposition systems (EM SCD500, Leica ${ }^{\oplus}$, Germany). The sputtered specimens were imaged using the scanning electron microscopes (Sigma VP, Zeiss ${ }^{\circledast}$, Germany) at secondary electron mode. 


\subsection{Statistical Analysis}

Statistical analysis was performed with GraphPad Prism (version 7.00, GraphPad Software, San Diego, CA, U.S.A) with unpaired t-tests. Confidence level was 95\%.

\section{Results}

\subsection{Initial Mechanical Properties}

The initial mechanical properties of as-prepared composites are shown in Figure 1. As weight fraction of nano-HA in matrices increased from $0 \%$ to $20 \%$, a gradual increase of average flexural strengths from $236.31 \pm 10.83 \mathrm{MPa}$ to $310.55 \pm$ 22.88 $\mathrm{MPa}$ was observed. Comparing to the control group (bi-phase PGF/PLA composites with $0 \%$ nano-HA), the relative increment of flexural strengths are approximately $9 \%, 11 \%, 19 \%$ and $31 \%$ as nano-HA loading increased by every $5 \%$, respectively. On the other hand, the flexural modulus are improved from $8.70 \pm 0.35 \mathrm{GPa}$ to $14.97 \pm 1.30 \mathrm{GPa}$ as nano-HA contents increased by every $5 \%$, which are $15 \%, 19 \%, 29 \%$ and $72 \%$ higher than the control group. The enhancement of flexural modulus are statistically significant in specimens containing $15 \%$ and $20 \%$ nano-HA in matrices ( $p<0.05$, $\mathrm{t}$-test).

\subsection{Degradation of Mechanical Properties}

Mechanical properties during the 28-day degradation period were also characterized at 7 time points, except for specimens with $20 \mathrm{wt} \%$ nano-HA, as break down of specimens are found after 11 days of degradation, resulting in insufficient valid specimens for testing. As shown in Figure 2, flexural strengths of these composites all decreased due to degradation. Composites with 5 and 10 wt\% nano-HA maintained higher flexural strengths comparing to control group by Day 11, yet no statistical significance is confirmed ( $p>0.05$, t-test). Beyond this time point, the control group showed the highest flexural strengths and finally dropped to a similar level with others on Day 28. Composites with 15 and $20 \mathrm{wt} \%$ nano-HA presented much higher initial flexural strengths at the beginning, however, reduced drastically as soon as within 1 day, especially for specimens with $20 \mathrm{wt} \%$ nano-HA with their strengths almost halved. The reduction continued and average strengths fell below that of the control group after Day 3.

Reduction of modulus is similar to strength reduction (see Figure 3). For composite with less than $10 \mathrm{wt} \%$ nano-HA loading, the flexural modulus reduced quickly to $\sim 3 \mathrm{GPa}$ after 14 days, with no statistical significance observed in this period. In contrary, flexural modulus of composites with 15 and $20 \mathrm{wt} \%$ nano-HA loading are significantly lower ( $\mathrm{p}<0.05$, t-test) than control group since Day 3, suggesting a catastrophic reduction of stiffness in a short time.

\subsection{Water Absorption, Mass Loss of Composites and pH Value of Immersion Media}

The water absorption profile is diagrammed in Figure 4. In general, water absorption occurred within the first 24 hours of immersion in PBS and continued 
going up in the whole degradation period. Comparing to the control group, specimens with 5 and $10 \mathrm{wt} \%$ nano-HA showed slightly higher water absorption. In contrast, specimens with 15 and $20 \mathrm{wt} \%$ nano-HA loading showed much higher water uptake percentage comparing to other composites during the whole degradation period, especially for specimens with $20 \mathrm{wt} \%$ nano-HA, which showed the highest water uptake and remained significantly higher than other groups in the whole period ( $\mathrm{p}<0.05$, t-test). In summary, water absorption increased during composite degradation, and more importantly, with higher nano-HA contents in the composites.

Figure 5 depicted the mass loss profile after degradation. In general, mass loss increased during the period of degradation, with strongly significant $(\mathrm{p}<0.01$, t-test) mass loss observed from all composites after 3 days of immersion in PBS. However, no obvious relationship between mass loss and nano-HA contents was observed in the current study.

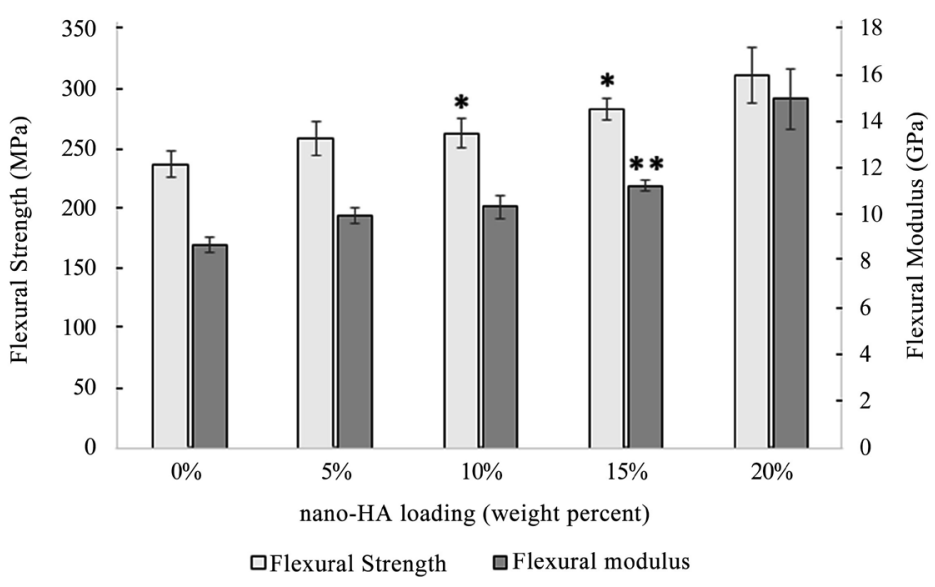

Figure 1. Initial mechanical properties of hybrid composites with different nano-HA contents. Error bars represent standard error $(n=3){ }^{*}$ : statistically significant ( $\mathrm{p}<0.05$, t-test), ${ }^{* *}$ : strongly statistically significant $(\mathrm{p}<0.01$, t-test), comparing to values of control groups (where nano-HA contents $=0 \%$ ).

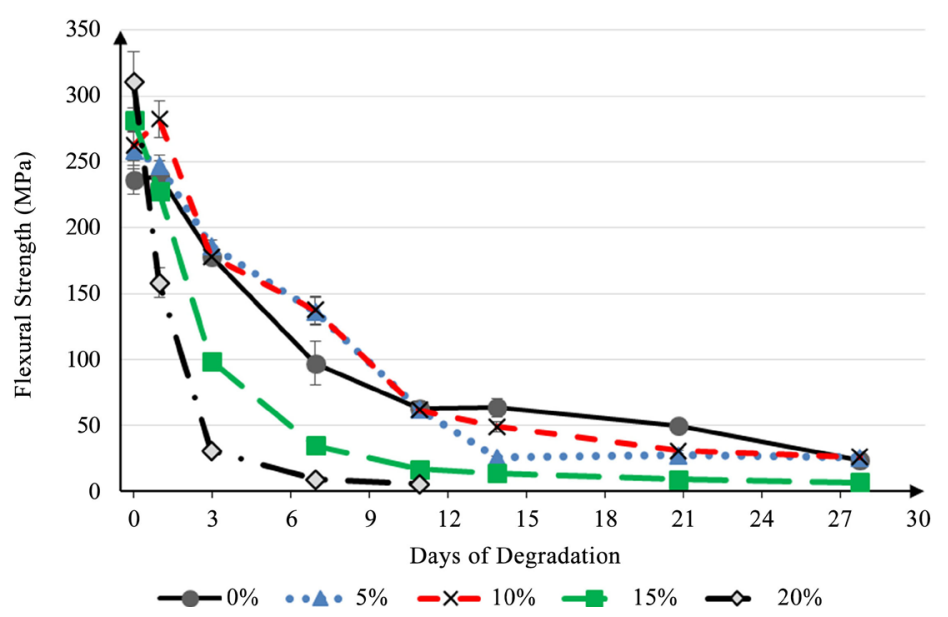

Figure 2. Degradation of flexural strengths in hybrid composites with different nano-HA contents in matrices. Error bars represent standard errors $(n=3)$. 


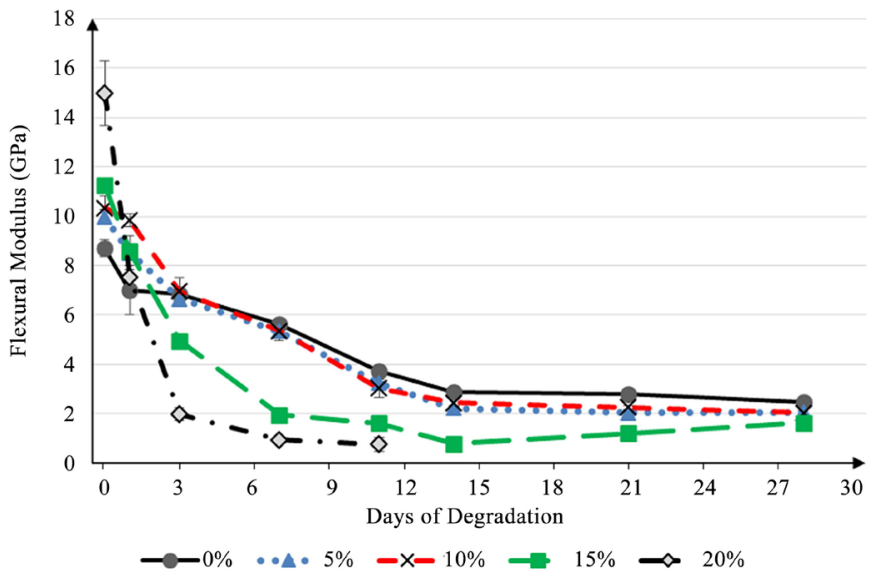

Figure 3. Degradation of flexural moduli in hybrid composites with different nano-HA contents in matrices. Error bars represent standard errors $(n=3)$.

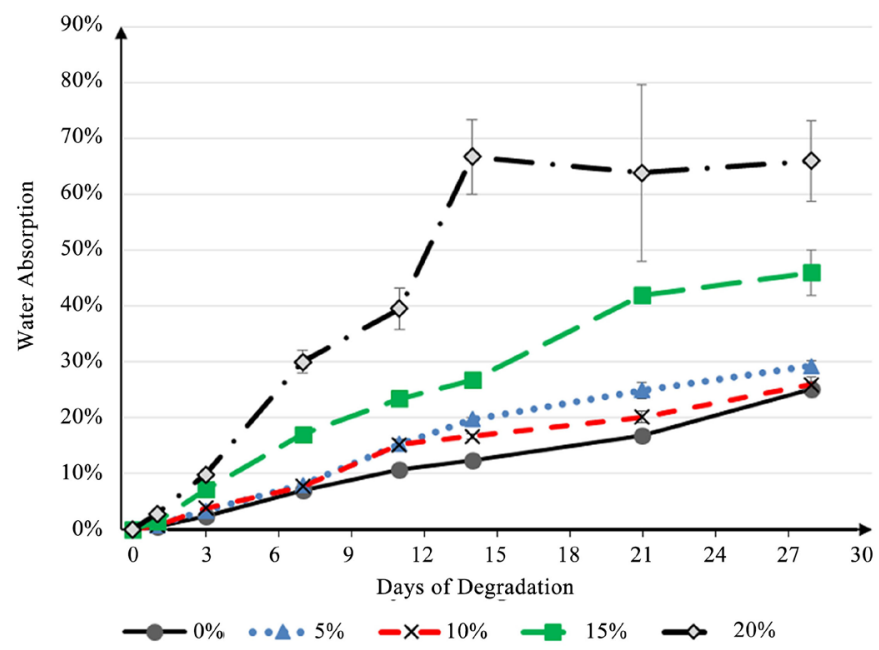

Figure 4. Water absorption profile of hybrid composites with different nano-HA contents in matrices. Error bars represent standard errors $(n=3)$.

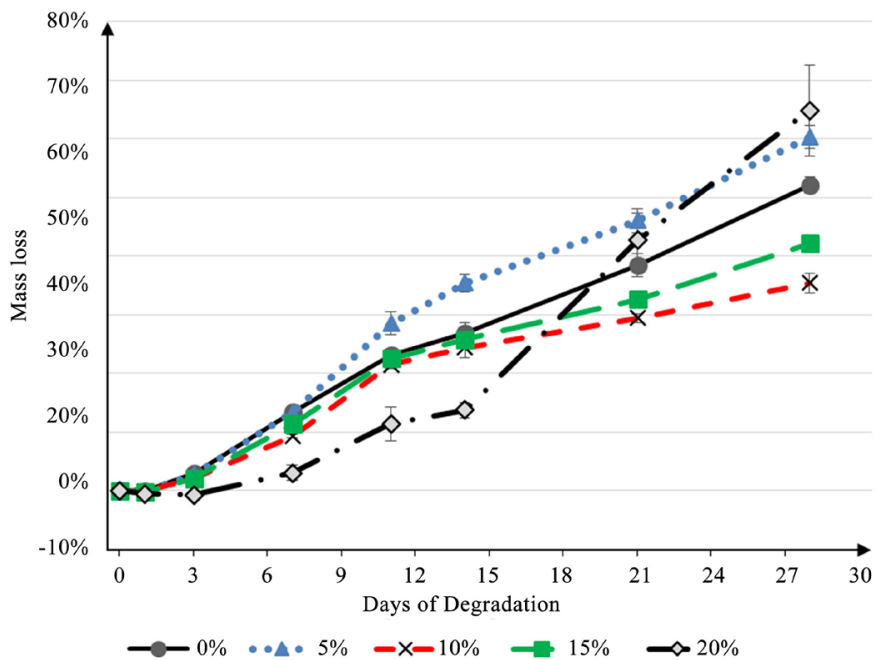

Figure 5. Mass loss profile of hybrid composites with different nano-HA contents in matrices. Error bars represent standard errors $(n=3)$. 
The $\mathrm{pH}$ values of immersion media are recorded and shown in Figure 6. Generally, the $\mathrm{pH}$ value decreased in the first 14 days of degradation studies, then gradually increased (as compensated with the replenishment of immersion media) to $\sim 7.0$ during Day 14 to Day 28. The lowest average $\mathrm{pH}$ recorded in this study was $5.81 \pm 0.06$ from composites with $5 \mathrm{wt} \%$ nano-HA on Day 14 . No significant relationship between $\mathrm{pH}$ and nano-HA content is confirmed.

\subsection{Appearance of Degraded Composites}

The photos of degraded composites are shown in Figure 7. For composites with $0 \%-15 \%$ loading of nano-HA, degradation of PGF can be clearly seen starting from the cut edges and developed into the centre of specimens. When the nano-HA content was $20 \mathrm{wt} \%$, severe failure of composites including significant swelling (Day 14) and total crush (Day 21) are shown in Figure 7C.

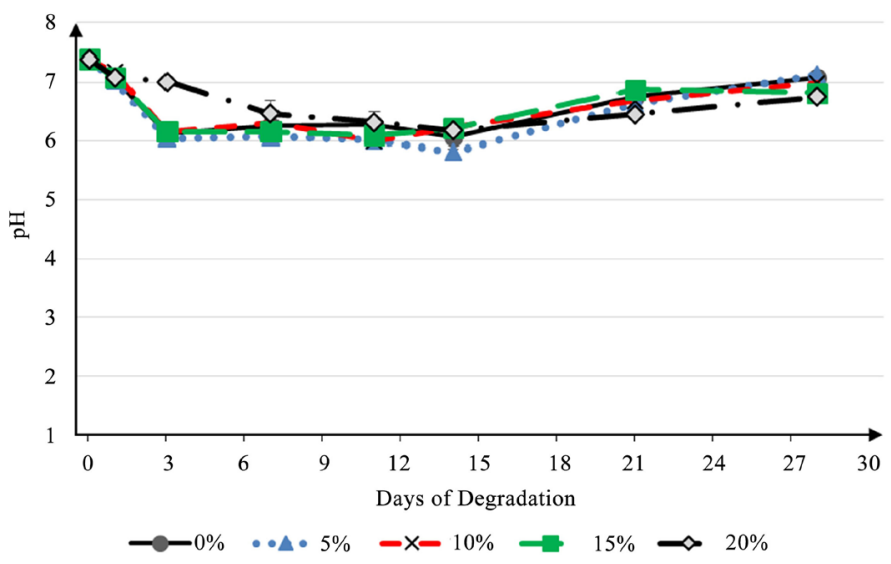

Figure 6. $\mathrm{pH}$ profile of immersion media for hybrid composites with different nano-HA contents in matrices. Error bars represent standard errors $(n=3)$.

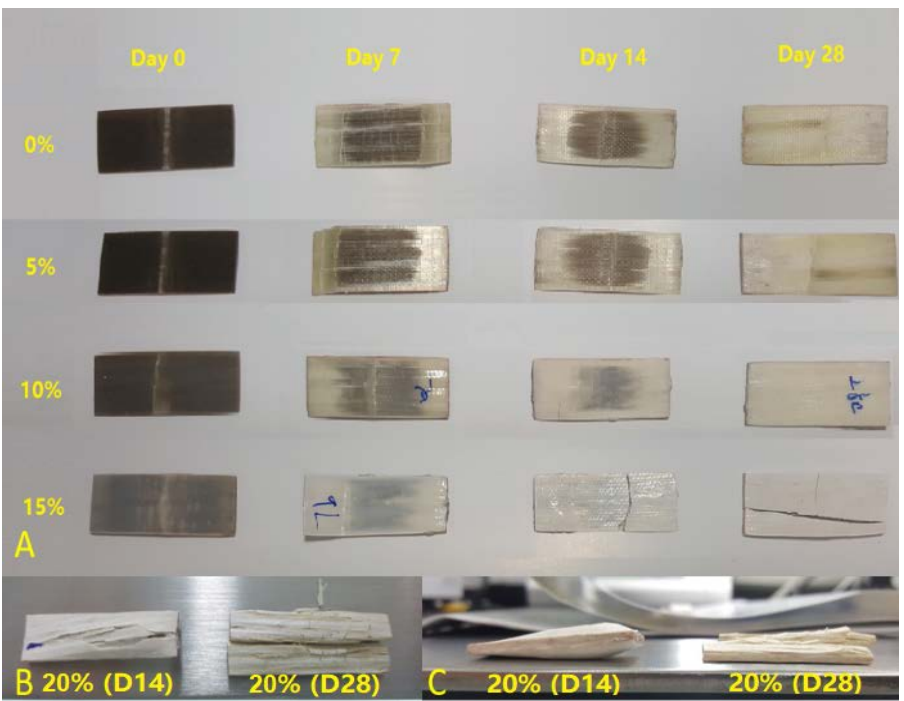

Figure 7. Photos of specimens with $0-15 \mathrm{wt} \%$ nano-HA in matrices at the different stages of degradation (A), and photos of degraded specimens with $20 \mathrm{wt} \%$ nano-HA in the matrices on Day 14 (left) and Day 28 (right), in top view (B) and front view (C). 


\subsection{SEM Imaging}

The SEM images of pristine fractured surfaces after 3-point bending tests as well as the polished cross-sections of the composites are shown in Figure 8. As nano-HA loading is below $5 \mathrm{wt} \%$, fractured PGFs are clearly seen at the pristine fractured surfaces of composites. For specimens with 10 and $15 \mathrm{wt} \%$ nano-HA, pulled-out fibres as well as voids left by these fibres are observed. When nano-HA loading increased to $20 \mathrm{wt} \%$, loose fibre bundles without resin impregnation are found from the fractured surface. For the ground-polished cross-sections of composites, it is clearly seen that fibres were generally well-embedded in the matrix when the nano-HA loading was below $10 \mathrm{wt} \%$. Voids are found surrounding the PGF the nano-HA content increased to $15 \mathrm{wt} \%$. With further increased nano-HA content of $20 \mathrm{wt} \%$, it is clearly seen that the fibres were surrounded by voids without being impregnated with the nano-HA/PLA matrix.

Two images of typical degraded specimens were shown in Figure 9. For specimens with $5 \mathrm{wt} \%$ nano-HA loading, struts of PGF showing weakened interface was seen after 3 days of degradation. This is a typically found appearance in composites with less than $10 \mathrm{wt} \%$ nano-HA loading. In the case of composites with 15 or $20 \mathrm{wt} \%$ nano-HA, however, layers of PGF bundles delaminated from the polymer-rich matrix, as seen in Figure 9(b).

\section{Discussion}

\subsection{Initial Mechanical Properties}

As indicated in numerous publications [14] [30] [31] [32], the materials designated for the bone fixation should possess similar mechanical properties as human cortical bones, in other words, flexural strengths of 50 - $150 \mathrm{MPa}$ and flexural modulus of 7 - $30 \mathrm{GPa}$ [8]. Comparing to these values, the mechanical properties of all hybrid composites investigated in this study are bone-mimicking and therefore suitable for the application of long/load-bearing bone fixation. These results are much superior to most of the HA/PLA binary composites reviewed, and similar to those ternary HA/PLA composites with fibres reinforcements.

It is found that both flexural modulus and flexural strength of hybrid composite are improved with higher nano-HA loading. The two properties are both important index to evaluate the load bearing properties of biomedical implants, with the strength as an indicator of ability to resist fracture and the modulus as an indicator of ability to resist deformation. However, the two properties are not necessarily correlated in polymer-based composites [33], and the effects of varying loadings of particulate reinforcements must be independently discussed.

It is known that the hydroxyapatite possesses high Young's modulus of 80 $110 \mathrm{GPa}$, which is much higher than that of PLA alone (3.6 GPa,) [13] [34]. Therefore, the stiffness of HA/PLA composites is improved with increasing loading of the rigid particles of HA [33] [35], which has been demonstrated with numerous HA/PLA composites regardless of the manufacturing method [9] [11] [14]. Given that the modulus and contents of fibre reinforcements remained 
constant, the flexural modulus becomes higher as the stiffness of the matrix is improved [17] [36].

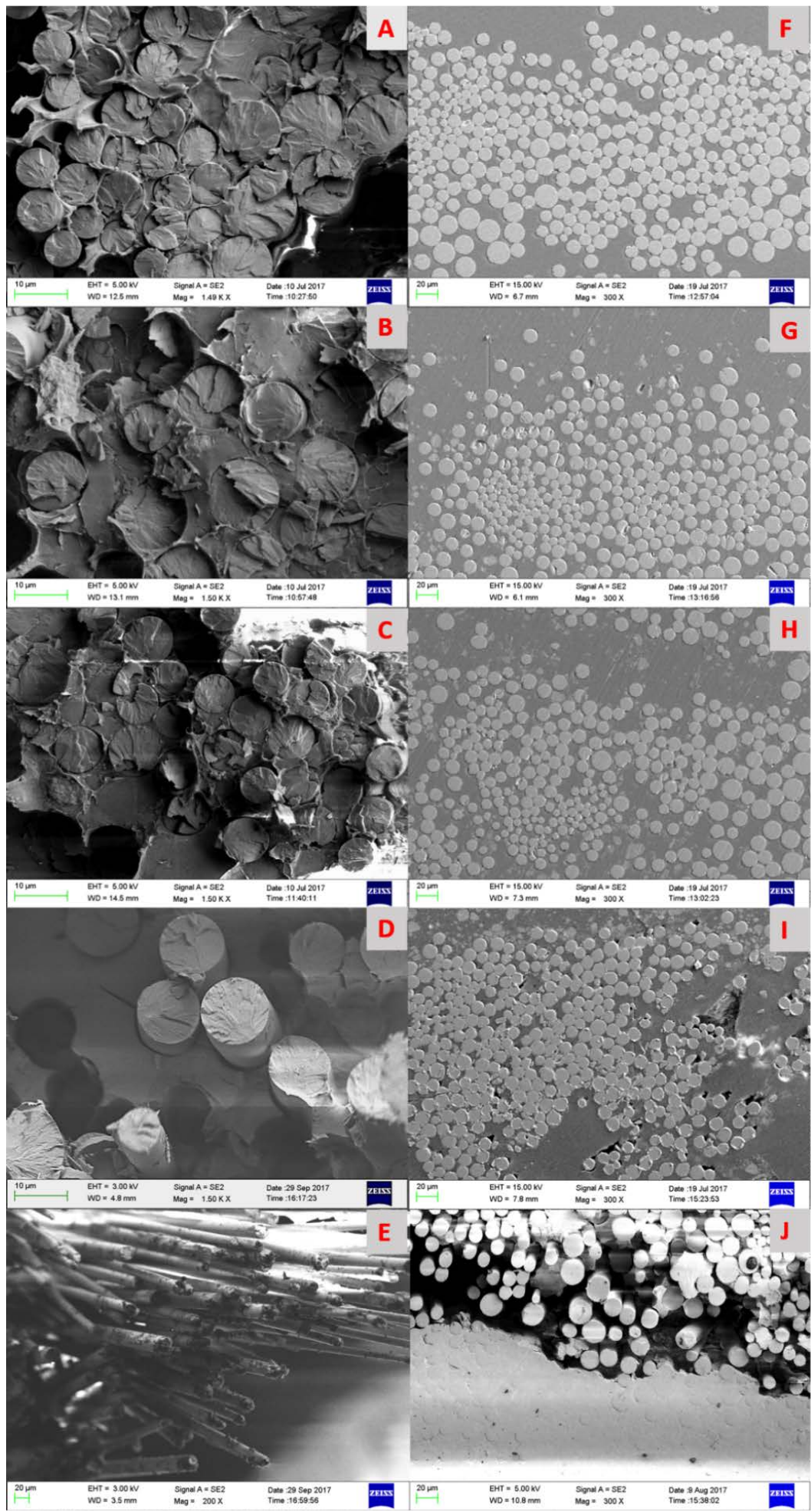

Figure 8. Fractured surfaces (A-E) and ground polished cross-sections of specimens (F-J), with 0 wt\% (A, F), 5 wt\% (B, G), 10 wt\% (C, H), 15 wt\% (D, I) and 20 $\mathrm{wt} \%$ (E, J) nano-HA loading in matrices. 


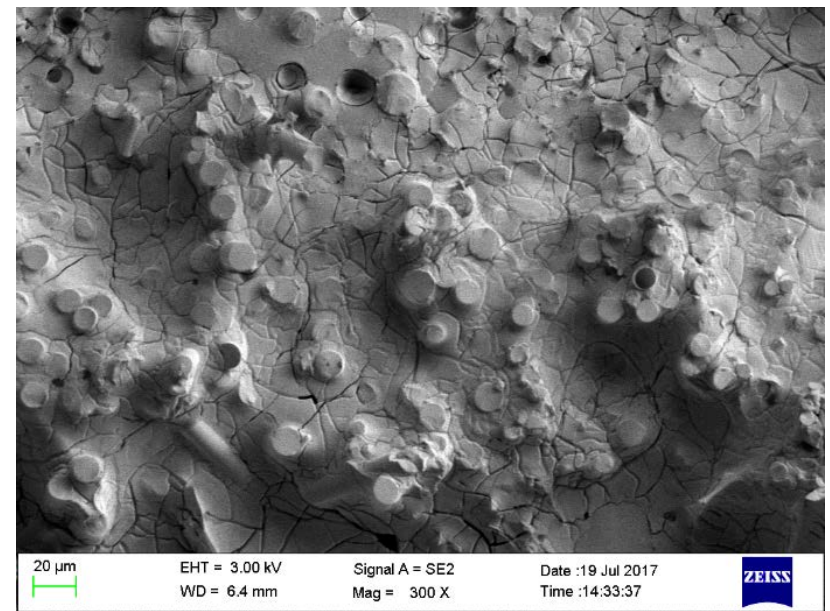

(a)

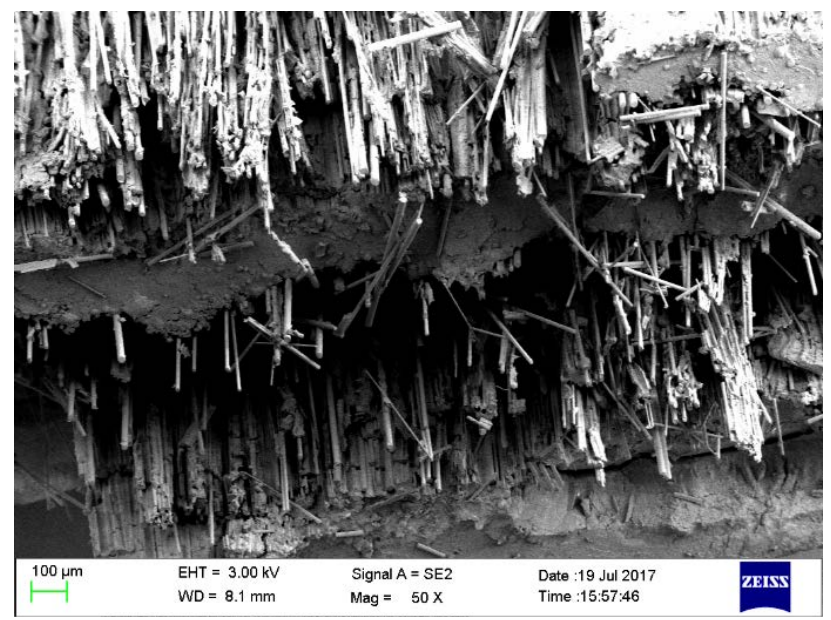

(b)

Figure 9. Fractured surfaces of specimens with $5 \mathrm{wt} \%$ (a) and 20 wt\% (b) nano-HA loading after 3 days of degradation in PBS.

The flexural strengths of the composites are also improved with increasing the nano-HA loading. Unlike the relationship between the nano-HA loading and modulus of composites, there is no absolute relationship between the strength of composites and nano-HA content. Shen et al. reported that for the nano-HA/carbon fibre/PLA composites, the flexural strengths increased as nano-HA loading increased from 0 to $15 \mathrm{wt} \%$, beyond which the strengths dropped significantly [17]. Similarly, Hong et al. reported a much lower critical nano-HA content of $5 \mathrm{wt} \%$ in their HA/PLA composites [11]. In other studies, however, the strength of composites reduced as micro/nanoparticles of HA content increased [9] [35]. This is also reported in our previous study investigating the E-glass fibre/nano-HA/PLA ternary composites [37]. The reason for this complication is related to many factors, including the interfacial strength between $\mathrm{HA}$ and matrix polymer as well as the dispersion of HA in composites. In general, a good interfacial strength and uniform dispersion of particulate reinforcements in the polymer are desired for strengthened composites. However, the 
high surface energy and hydrophilicity of HA facilitates the agglomeration of HA in PLA, which is a hydrophobic polymer. The agglomerates of HA might easily lead to stress concentration in composites and facilitates the failure of composites [33]. Back to the current study, the gradual increments of flexural strengths are found with increasing nano-HA loading. Comparing the methods applied in our previous study of E-glass fibres/nano-HA/PLA composites, an additional ultra-sonication process was applied to the nano-HA/PLA/DCM slurries during the preparation of nanocomposite matrices. This process is considered to have dispersed the nano-HA particles homogeneously without severe agglomeration, consequently help to strengthen the composites.

\subsection{Degradation of Hybrid Composites}

For all the composites prepared, deterioration of flexural properties is confirmed since the first day of immersion in PBS, and 50\% reduction of both strengths and moduli are recorded by the $11^{\text {th }}$ day of degradation. The significant reduction of flexural properties within such a short period is attributed to the open ends of composite specimens, which expose the PGF and fibre-matrix interface to the degradation medium. As such, wicking of water along the unidirectional fibres occurred from the outer area into the central part of test specimens, as seen in Figure 7A. In addition, compromised interface strength was resulted, indicated by the struts of pulled-out fibres (instead of fractured fibres before degradation) in Figure 9(a) [19].

The variation of flexural properties indicates that the degradation rates are levelled up with increasing nano-HA loading. While no significant difference among composites with 0 to $10 \mathrm{wt} \%$ nano-HA content is confirmed, catastrophic degradation is found from composites with 15 and $20 \mathrm{wt} \%$ nano-HA loading, whose flexural properties reduced by more than $60 \%$ in 3 days, comparing to no more than $32 \%$ reduction of strengths and modulus from the other three groups. The extreme case is the composite with $20 \mathrm{wt} \%$ nano-HA loading, as only $10 \%$ of initial flexural modulus survived on Day 3. Meanwhile, the mass loss profile of composites and moderate $\mathrm{pH}$ variation was recorded, suggesting that the dissolution of PGF is unlikely to account for this quick degradation.

There are two possible reasons for the accelerated degradation with increased nano-HA loading. The first one is related to the enhanced hydrolysis at the fibre-matrix interface due to increased water uptake ability induced by nano-HA. Lin et al. reported that mass loss and $\mathrm{pH}$ reduction were more pronounced from composites with higher HA contents and suggested that the surface area of PLA in contact with immersion media is increased as an effect of increased HA incorporation. As a consequence, degradation of composites is accelerated with increasing HA loading [38]. It is known that hydroxyapatite was hydrophilic, and the surface wettability of HA/PLA composites with higher HA loading is found to increase [39] [40]. Therefore, the water infusion is facilitated in composites with higher nano-HA loading, and the hydrolysis at the fibre-matrix is 
consequently intensified. Another possible reason for the accelerated degradation is attributed to the internal structures of composites. In Figure 8(I) and Figure $8(\mathrm{~J})$, voids as well as loose fibres are clearly seen from the cross-sections of composites containing 15 and $20 \mathrm{wt} \%$ nano-HA, suggesting that the impregnation of PGF were poor in these composites. These voids might act as channels allowing water infusion into the centre of composites, thus accelerating the degradation. In addition, the incorporation of nano-HA and their agglomerates might also create penetration sites for water infusion, thus facilitating the degradation of composites [41].

The degradation behaviour is an important aspect of biodegradable orthopaedic implants. The desirable degradation manner is slow, gradual deterioration of mechanical properties that allow the mechanical load to be gradually taken by newly grown bones, thus providing necessary stimulus for bone with load-bearing capacity to be regenerated [5]. In contrast, the quick loss of mechanical properties and failure of the implant (e.g. premature break down/deformation) must be avoided to avoid failure of bone fixation. In the current study, while the initial mechanical properties of composites benefited from increasing nano-HA contents, the degradation of hybrid composites is found dramatically accelerated when the nano-HA loading exceeds $15 \mathrm{wt} \%$. Therefore, the nano-HA loading must be strictly controlled to achieve the optimal reinforcement of initial mechanical properties of hybrid composites without causing the catastrophic degradation of composites shortly after implantation. From the current study, the optimal nano-HA loading is $10 \mathrm{wt} \%$ (regarding the nano-HA loading in HA/PLA composite matrix), as the initial flexural strength/modulus were reinforced to the maximum extent, while the degradation rate was similar with the control group without catastrophic breakdown/deformation observed.

\subsection{Wetting of PGF by Nano-HA/PLA Matrices}

It is known that interfacial bonding determined both the initial mechanical properties as well as the degradation term of PGF reinforced composites [22] [24]. An important issue is how well the fibres are bonded to the matrices. From the SEM images of ground polished cross-sections, cracks and voids surrounding fibres are observed with nano-HA incorporation higher than 15\%, indicating that the wetting of fibres is incomplete in these cases. The reason for the incomplete impregnation is due to the reduced flowing ability of moltenpolymer matrix with high nano-HA contents. It was previously reported that with the increasing addition of HA particles, the viscosity of polymer blends increased [41] [42]. The increased viscosity of the HA/PLA matrix (in the form of melts) hinders the wetting of fibres. Similarly, Vlasveld and colleagues also reported that melt viscosity of silicate/PA-6 composites increased with higher nanosilicate content. With a very high loading of layered silicate (10 wt\%), poor fibre wetting as well as voids were observed in their composites [43] [44]. Besides the amount of impregnated fibres, further study is required to investigate how strong is the 
fibre-matrix bonding, as this is an important factor that might affect both the initial mechanical properties and degradation rate of composites.

\section{Conclusion}

In this study, the mechanical properties as well as in-vitro degradation behaviour of the hybrid composites of nano-HA/PGF/PLA are investigated for the first time. With increasing nano-HA contents in the HA/PLA matrices, both the initial flexural strengths and modulus increased as a result, matching the reported mechanical properties of human cortical bones. From the view of in-vitro degradation, the degradation rates are similar among composites with 0,5 and 10 wt $\%$ nano-HA loading. However, as nano-HA loading exceeds $15 \mathrm{wt} \%$, the degradation of hybrid composites is dramatically accelerated, with extreme case being the premature break down of composites with $20 \mathrm{wt} \%$ nano-HA after 11 days of immersion in PBS. The improved water uptake ability is found correlated with the increasing nano-HA contents, which might lead to accelerated degradation. Moreover, the addition of excessive nano-HA led to the reduced flowing ability of HA/PLA composite melts during the compression moulding process, resulting in poor wetting of composites at high HA loading. The nano-HA loading of $10 \mathrm{wt} \%$ is considered the optimal loading due to the greatest extent of initial mechanical reinforcement achieved without catastrophic degradation. Further study is required to characterize the bonding strength as well as optimize the manufacturing protocol in order to enhance the mechanical properties and their endurance against degradation.

\section{Acknowledgements}

The authors would like to thank Sinoma Co., Ltd. for kindly providing phosphate glass fibres for this study. This study is financially supported by the Ningbo 3315 Innovation team Scheme "Marine Composites Development and Manufacturing for Sustainable Environment", as well as the Ningbo S \& T bureau Ningbo International Collaboration Project (Project Code 2017D10012).

\section{Conflicts of Interest}

The authors declare no conflicts of interest regarding the publication of this paper.

\section{References}

[1] Ducheyne, P. (2011) Comprehensive Biomaterials. 1st Edition, Elsevier, Amsterdam.

[2] Asri, R.I.M., Harun, W.S.W., Samykano, M., Lah, N.A.C., Ghani, S.A.C., Tarlochan, F. and Raza, M.R. (2017) Corrosion and Surface Modification on Biocompatible Metals: A Review. Materials Science and Engineering: C, 77, 1261-1274. https://doi.org/10.1016/j.msec.2017.04.102

[3] Koh, J., Berger, A. and Benhaim, P. (2015) An Overview of Internal Fixation Implant Metallurgy and Galvanic Corrosion Effects. The Journal of Hand Surgery, 40, 1703-1710.e4. 
[4] Fouad, H. (2010) Effects of the Bone-Plate Material and the Presence of a Gap between the Fractured Bone and Plate on the Predicted Stresses at the Fractured Bone. Medical Engineering \& Physics, 32, 783-789. https://doi.org/10.1016/j.medengphy.2010.05.003

[5] Middleton, J.C. and Tipton, A.J. (2000) Synthetic Biodegradable Polymers as Orthopedic Devices. Biomaterials, 21, 2335-2346.

https://doi.org/10.1016/S0142-9612(00)00101-0

[6] Fonseca, A.C., Gil, M.H. and Simões, P.N. (2014) Biodegradable Poly(Ester Amide)s: A Remarkable Opportunity for the Biomedical Area: Review on the Synthesis, Characterization and Applications. Progress in Polymer Science, 39, 1291-1311. https://doi.org/10.1016/j.progpolymsci.2013.11.007

[7] Zhou, H., Lawrence, J.G. and Bhaduri, S.B. (2012) Fabrication Aspects of PLA-CaP/PLGA-CaP Composites for Orthopedic Applications: A Review. Acta Biomaterialia, 8, 1999-2016. https://doi.org/10.1016/j.actbio.2012.01.031

[8] Colquhoun, R. and Tanner, K.E. (2015) Mechanical Behaviour of Degradable Phosphate Glass Fibres and Composites: A Review. Biomedical Materials, 11, 014105. https://doi.org/10.1088/1748-6041/11/1/014105

[9] Damadzadeh, B., Jabari, H., Skrifvars, M., Airola, K., Moritz, N. and Vallittu, P.K. (2010) Effect of Ceramic Filler Content on the Mechanical and Thermal Behaviour of Poly-L-Lactic Acid and Poly-L-Lactic-Co-Glycolic Acid Composites for Medical Applications. Journal of Materials Science: Materials in Medicine, 21, 2523-2531. https://doi.org/10.1007/s10856-010-4110-9

[10] Kasuga, T., Ota, Y., Nogami, M. and Abe, Y. (2000) Preparation and Mechanical Properties of Polylactic Acid Composites Containing Hydroxyapatite Fibers. Biomaterials, 22, 19-23. https://doi.org/10.1016/S0142-9612(00)00091-0

[11] Hong, Z., Zhang, P., He, C., Qiu, X., Liu, A., Chen, L., Chen, X. and Jing, X. (2005) Nano-Composite of Poly(L-Lactide) and Surface Grafted Hydroxyapatite: Mechanical Properties and Biocompatibility. Biomaterials, 26, 6296-6304. https://doi.org/10.1016/j.biomaterials.2005.04.018

[12] Aydin, E., Planell, J.A. and Hasirci, V. (2011) Hydroxyapatite Nanorod-Reinforced Biodegradable Poly(L-Lactic Acid) Composites for Bone Plate Applications. Journal of Materials Science: Materials in Medicine, 22, 2413-2427. https://doi.org/10.1007/s10856-011-4435-Z

[13] Petricca, S.E., Marra, K.G. and Kumta, P.N. (2006) Chemical Synthesis of Poly(Lactic-Co-Glycolic Acid)/Hydroxyapatite Composites for Orthopaedic Applications. Acta Biomaterialia, 2, 277-286. https://doi.org/10.1016/j.actbio.2005.12.004

[14] Shikinami, Y. and Okuno, M. (1999) Bioresorbable Devices Made of Forged Composites of Hydroxyapatite (HA) Particles and Poly l-Lactide (PLLA). Part I: Basic Characteristics. Biomaterials, 20, 859-877. https://doi.org/10.1016/S0142-9612(98)00241-5

[15] Hasegawa, S., Ishii, S., Tamura, J., Furukawa, T., Neo, M., Matsusue, Y., Shikinami, Y., Okuno, M. and Nakamura, T. (2006) A 5 - 7 Year in Vivo Study of High-Strength Hydroxyapatite/Poly(L-Lactide) Composite Rods for the Internal Fixation of Bone Fractures. Biomaterials, 27, 1327-1332.

https://doi.org/10.1016/j.biomaterials.2005.09.003

[16] Shikinami, Y., Matsusue, Y. and Nakamura, T. (2005) The Complete Process of Bioresorption and Bone Replacement Using Devices Made of Forged Composites of Raw Hydroxyapatite Particles/Poly L-lactide (F-u-HA/PLLA). Biomaterials, 26, 5542-5551. https://doi.org/10.1016/j.biomaterials.2005.02.016 
[17] Shen, L., Yang, H., Ying, J., Qiao, F. and Peng, M. (2009) Preparation and Mechanical Properties of Carbon Fiber Reinforced Hydroxyapatite/Polylactide Biocomposites. Journal of Materials Science: Materials in Medicine, 20, 2259-2265. https://doi.org/10.1007/s10856-009-3785-2

[18] Su, B., Peng, X., Jiang, D., Wu, J., Qiao, B., Li, W. and Qi, X. (2013) In Vitro and in Vivo Evaluations of Nano-Hydroxyapatite/Polyamide 66/Glass Fibre (n-HA/PA66/ GF) as a Novel Bioactive Bone Screw. PLoS ONE, 8, e68342. https://doi.org/10.1371/journal.pone.0068342

[19] Ahmed, I., Jones, I.A., Parsons, A.J., Bernard, J., Farmer, J., Scotchford, C.A., Walker, G.S. and Rudd, C.D. (2011) Composites for Bone Repair: Phosphate Glass Fibre Reinforced PLA with Varying Fibre Architecture. Journal of Materials Science: Materials in Medicine, 22, 1825-1834. https://doi.org/10.1007/s10856-011-4361-0

[20] Parsons, A.J., Ahmed, I., Haque, P., Fitzpatrick, B., Niazi, M.I.K., Walker, G.S. and Rudd, C.D. (2009) Phosphate Glass Fibre Composites for Bone Repair. Journal of Bionic Engineering, 6, 318-323. https://doi.org/10.1016/S1672-6529(08)60132-8

[21] Haque, P., Parsons, A.J., Barker, I.A., Ahmed, I., Irvine, D.J., Walker, G.S. and Rudd, C.D. (2010) Interfacial Properties of Phosphate Glass Fibres/PLA Composites: Effect of the End Functionalities of Oligomeric PLA Coupling Agents. Composites Science and Technology, 70, 1854-1860. https://doi.org/10.1016/j.compscitech.2010.06.012

[22] Hasan, M.S., Ahmed, I., Parsons, A.J., Walker, G.S. and Scotchford, C.A. (2013) The Influence of Coupling Agents on Mechanical Property Retention and Long-Term Cytocompatibility of Phosphate Glass Fibre Reinforced PLA Composites. Journal of the Mechanical Behavior of Biomedical Materials, 28, 1-14. https://doi.org/10.1016/j.jmbbm.2013.07.014

[23] Hasan, M.S., Ahmed, I., Parsons, A., Walker, G. and Scotchford, C. (2012) Cytocompatibility and Mechanical Properties of Short Phosphate Glass Fibre Reinforced Polylactic Acid (PLA) Composites: Effect of Coupling Agent Mediated Interface. Journal of Functional Biomaterials, 3, 706-725. https://doi.org/10.3390/jfb3040706

[24] Liu, X., Grant, D.M., Parsons, A.J., Harper, L.T., Rudd, C.D. and Ahmed, I. (2013) Magnesium Coated Bioresorbable Phosphate Glass Fibres: Investigation of the Interface between Fibre and Polyester Matrices. BioMed Research International, 2013, Article ID: 735981. https://doi.org/10.1155/2013/735981

[25] Liu, X., Hasan, M.S., Grant, D.M., Harper, L.T., Parsons, A.J., Palmer, G., Rudd, C.D. and Ahmed, I. (2014) Mechanical, Degradation and Cytocompatibility Properties of Magnesium Coated Phosphate Glass Fibre Reinforced Polycaprolactone Composites. Journal of Biomaterials Applications, 29, 675-687. https://doi.org/10.1177/0885328214541302

[26] Felfel, R.M., Ahmed, I., Parsons, A.J. and Rudd, C.D. (2013) Bioresorbable Screws Reinforced with Phosphate Glass Fibre: Manufacturing and Mechanical Property Characterisation. Journal of the Mechanical Behavior of Biomedical Materials, 17, 76-88. https://doi.org/10.1016/j.jmbbm.2012.08.001

[27] Felfel, R.M., Ahmed, I., Parsons, A.J., Walker, G.S. and Rudd, C.D. (2011) In Vitro Degradation, Flexural, Compressive and Shear Properties of Fully Bioresorbable Composite Rods. Journal of the Mechanical Behavior of Biomedical Materials, 4, 1462-1472. https://doi.org/10.1016/j.jmbbm.2011.05.016

[28] Zhu, C., Ahmed, I., Parsons, A., Hossain, K.Z., Rudd, C., Liu, J. and Liu, X. (2017) Structural, Thermal, in Vitro Degradation and Cytocompatibility Properties of $\mathrm{P}_{2} \mathrm{O}_{5}-\mathrm{B}_{2} \mathrm{O}_{3}-\mathrm{CaO}-\mathrm{MgO}-\mathrm{Na}_{2} \mathrm{O}-\mathrm{Fe}_{2} \mathrm{O}_{3}$ Glasses. Journal of Non-Crystalline Solids, 457, 
77-85. https://doi.org/10.1016/j.jnoncrysol.2016.11.001

[29] SIGMA-ALDRICH (2016) Dichloromethane: Safety Data Sheet. http://www.sigmaaldrich.com/MSDS/MSDS/DisplayMSDSPage.do?country=GB\&la $\underline{\text { nguage }}=$ en \&productNumber $=270997 \&$ brand $=$ SIAL\&PageToGoToURL $=$ http $\% 3 \mathrm{~A} \%$ 2F\%2Fwww.sigmaaldrich.com\%2Fcatalog\%2Fproduct\%2Fsial\%2F $270997 \% 3$ Flang\% 3Den

[30] Parsons, A.J., Ahmed, I., Han, N., Felfel, R. and Rudd, C.D. (2010) Mimicking Bone Structure and Function with Structural Composite Materials. Journal of Bionic Engineering, 7, S1-S10. https://doi.org/10.1016/S1672-6529(09)60211-0

[31] Harper, L.T., Ahmed, I., Felfel, R.M. and Qian, C. (2012) Finite Element Modelling of the Flexural Performance of Resorbable Phosphate Glass Fibre Reinforced PLA Composite Bone Plates. Journal of the Mechanical Behavior of Biomedical Materials, 15, 13-23. https://doi.org/10.1016/j.jmbbm.2012.07.002

[32] Daniels, A.U., Chang, M.K.O., Andriano, K.P. and Heller, J. (1990) Mechanical Properties of Biodegradable Polymers and Composites Proposed for Internal Fixation of Bone. Journal of Applied Biomaterials, 1, 57-78.

https://doi.org/10.1002/jab.770010109

[33] Fu, S.-Y., Feng, X.-Q., Lauke, B. and Mai, Y.-W. (2008) Effects of Particle Size, Particle/Matrix Interface Adhesion and Particle Loading on Mechanical Properties of Particulate-Polymer Composites. Composites Part B: Engineering, 39, 933-961. https://doi.org/10.1016/j.compositesb.2008.01.002

[34] Felfel, R.M., Hossain, K.M.Z., Parsons, A.J., Rudd, C.D. and Ahmed, I. (2015) Accelerated in Vitro Degradation Properties of Polylactic Acid/Phosphate Glass Fibre Composites. Journal of Materials Science, 50, 3942-3955. https://doi.org/10.1007/s10853-015-8946-8

[35] Ferri, J.M., Jordá, J., Montanes, N., Fenollar, O. and Balart, R. (2017) Manufacturing and Characterization of Poly(lactic acid) Composites with Hydroxyapatite. Journal of Thermoplastic Composite Materials, 31, 865-881.

[36] Betanzos, F.B., Gimeno-Fabra, M., Segal, J., Grant, D. and Ahmed, I. (2016) Cyclic Pressure on Compression-Moulded Bioresorbable Phosphate Glass Fibre Reinforced Composites. Materials and Design, 100, 141-150. https://doi.org/10.1016/j.matdes.2016.03.108

[37] He, L., Zhu, C., Cong, X., Rudd, C.D. and Liu, X. (2017) Hybrid Composites of Silica Glass Fibre/Nano-Hydroxyapatite/Polylactic Acid for Medical Application. The 21 st International Conference on Composite Materials, Xi'an, 20-25 August 2017.

[38] Lin, P.-L., Fang, H.-W., Tseng, T. and Lee, W.-H. (2007) Effects of Hydroxyapatite Dosage on Mechanical and Biological Behaviors of Polylactic Acid Composite Materials. Materials Letters, 61, 3009-3013. https://doi.org/10.1016/j.matlet.2006.10.064

[39] Xu, X., Chen, X., Liu, A., Hong, Z. and Jing, X. (2007) Electrospun Poly(L-Lactide)-Grafted Hydroxyapatite/Poly(L-Lactide) Nanocomposite Fibers. European Polymer Journal, 43, 3187-3196. https://doi.org/10.1016/j.eurpolymj.2007.05.024

[40] Liu, C., Chan, K.W., Shen, J., Wong, H.M., Kwok Yeung, K.W. and Tjong, S.C. (2015) Melt-Compounded Polylactic Acid Composite Hybrids with Hydroxyapatite Nanorods and Silver Nanoparticles: Biodegradation, Antibacterial Ability, Bioactivity and Cytotoxicity. RSC Advances, 5, 72288-72299. https://doi.org/10.1039/C5RA14155A

[41] Wang, M., Yue, C.Y. and Chua, B. (2001) Production and Evaluation of Hydroxyapatite Reinforced Polysulfone for Tissue Replacement. Journal of Materials Science: Materials in Medicine, 12, 821-826. https://doi.org/10.1023/A:1017933220894 
[42] Ahmad, M., Uzir Wahit, M., Abdul Kadir, M.R. and Mohd Dahlan, K.Z. (2012) Mechanical, Rheological, and Bioactivity Properties of Ultra High-Molecular Weight Polyethylene Bioactive Composites Containing Polyethylene Glycol and Hydroxyapatite. Scientific World Journal, 2012, Article ID: 474851. https://doi.org/10.1100/2012/474851

[43] Vlasveld, D.P.N., Parlevliet, P.P., Bersee, H.E.N. and Picken, S.J. (2005) Fibre-Matrix Adhesion in Glass-Fibre Reinforced Polyamide-6 Silicate Nanocomposites. Composites Part A: Applied Science and Manufacturing, 36, 1-11. https://doi.org/10.1016/S1359-835X(04)00186-1

[44] Daud, W., Bersee, H.E.N. and Adriaan, B. (2007) Nanocomposite Matrix for Improved Fiber Reinforced Composites Properties. The 16th International Conference on Composite Materials, Kyoto, 8-13 July 2007. 